\title{
A control strategy on power quality improvement in consumer side using custom power device
}

\author{
D Danalakshmi ${ }^{1}$, Srinivas Bugata ${ }^{2}$, Kohila $\mathbf{J}^{3}$ \\ ${ }^{1,2}$ Department of Electrical and Electronics Engineering, GMR Institute of Technology, India \\ ${ }^{3}$ Assistant professor, Kalasalingam Academy of Research \& Education, India
}

\begin{tabular}{l} 
Article Info \\
\hline Article history: \\
Received Dec 29, 2018 \\
Revised Feb 21, 2019 \\
Accepted Mar 2, 2019 \\
\hline
\end{tabular}

Keywords:

Custom power devices, Distribution static compensator

Dynamic voltage restorer

Power quality

Voltage sag

\begin{abstract}
At a recent time voltage distortion is one of the foremost power quality problem at all level of power system. Power electronic controllers like various filtering technology have been used for more desirable solution of power quality problems to users. But still there is a voltage and frequency deviations problem in the power system which leads to reduction in quality of power and thereby reduces the life of consumer equipment. To overcome this drawback and protects the sensitive loads from power quality problems, custom power devices are used. Among various custom power devices, Dynamic voltage restorer (DVR) is an ultimate solution to address the voltage correlated power quality problems. DVR is a usual three phase inverter which transforms DC to AC and vice-versa using DC link capacitor. Whenever utility is distorted by voltage correlated faults, DVR is dynamic and it shields the load from utility distortions. Whenever distortion arises, the control strategy for the DVR plays significant role to make the DVR in active condition. Among all control strategies, Synchronous reference frame theory is simple and suitable for DVR. The DVR topology is verified and validated using SIMULINK/MATLAB.
\end{abstract}

Copyright $(2019$ Institute of Advanced Engineering and Science. All rights reserved.

\section{Corresponding Author:}

Danalakshmi. D,

Department of Electrical and Electronics Engineering,

GMR Institute of Technology,

GMR Nagar, Rajam, Andhra Pradesh, India-532127.

Email: danalakshmi.d@gmrit.org

\section{INTRODUCTION}

Power quality refers to the ability of electrical equipment to consume the energy being supplied to it. The problem behind the power quality could be the light diming and the failure of consumer equipment. These problems are associated with voltage correlated issues like voltage sag, swell, harmonics, poor power factor, and voltage unbalance bearing on the efficiency of electrical equipment. At recent time, power quality is most complicated issues in consumer side [1-3]. These power quality issues are mitigated by using Custom power device (CPD) [4]. The various filtering technologies are used in power system to obtain desirable power quality. To overcome the drawbacks of instability and fixed compensation, active filters are used i.e. series, shunt and hybrid filters. Hybrid filter is the amalgamation of shunt filters and series filters. Passive filters are widely used to reduce the harmonics [5]. But still there is a voltage and frequency deviation problems in the power system which leads to failure of the consumer's equipment to reduce the power quality problem and increase the reliability of the system. Recently, an advanced power electronic controllers are launched and has given birth to custom power devices. As per the standards of IEEE and IEC standards, there is increasing trend towards the CPD in the distribution for effective voltage compensation. Figure 1 illustrates the classification of CPD and they are explained as follows. 


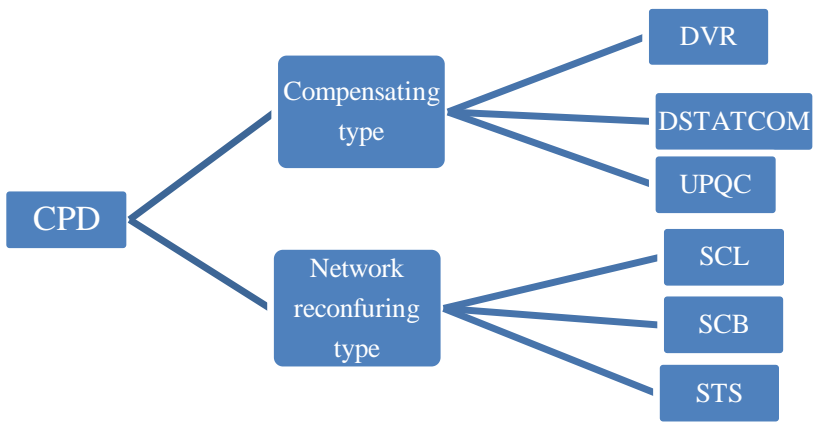

Figure 1. Classification of CPD [6]

Compensating devices are used for power factor correction and voltage balance [7]. These are mainly categorized into three type's i.e. Dynamic voltage restorer (DVR), Distribution static compensator (DSTATCOM) and Unified Power Quality Compensator (UPQC).

DVR is a series-connected converter [8-9] which protects sensitive electric equipment from power quality issues. The DVR provides the required amount of voltage and frequency in the load side. It is also known as static compensator and it can be used to compensate voltage sag as well as mitigate harmonic disturbances [10-12]. It is also used as high power electronic controlling device [13-14]. DVR is used for the harmonics reduction, fault current limitations and transient reductions. A DVR can be made up of an injection transformer, Voltage Source Converter (VSC), energy storage unit and filter which is shown in Figure 2 [15-17].

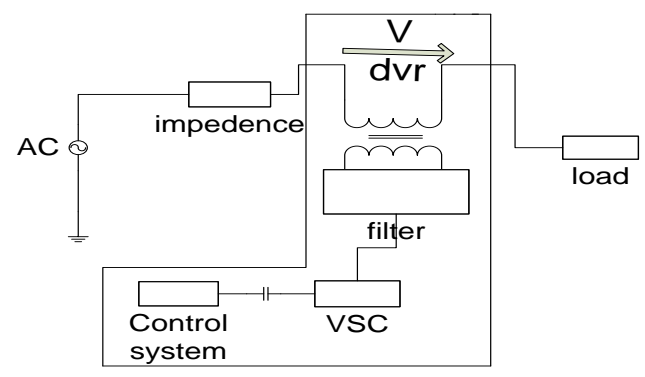

Figure 2. Block diagram of DVR [17]

Injection transformer restricts the noise and transfer energy from primary to secondary side. In accumulation, the Injection transformer assists for the persistence of isolation of the load from the system [18]. A VSC is a power converter which consists of storage and switching devices [19], it can generate required AC voltage [20-21]. It consistently performs energy storage and predominantly operated in balancing condition. Harmonic filter is used to accumulate the harmonic content produced by the VSC to the tolerable level.

DSTATCOM are used in the distribution side for enhancement of power quality [22]. It provides solution for power quality problems, power factor improvement and voltage regulation [23-24]. DSTATCOM is a shunt connected device consisting of VSC, storage device, filter and coupling transformer [25]. VSC converts the DC into balanced three phase AC voltages. These generated voltages are fed to the utility grid through coupling transformer.

UPQC appears to be a principally capable power conditioner device. UPQC can be made up of two VSI which is coupled to the incorporation of back to back series and shunt compensators through common DC bus voltage [26]. It is a device which can terminates the current in shunt and voltage in series simultaneously. UPQC balance the terminal voltage and exclude the negative zero sequence current at the similar period [27]. It is used to compensate voltage fluctuations and harmonics [28].

Network reconfuring type are usually gate turn off (GTO) based devices. These devices are used to limits the fault current, protection from voltage sag and swell. These are mainly categorized into three type's i.e. static current limiter (SCL), Static circuit breaker (SCB) and Static transfer switch (STS). 
SCL is used to prevent high fault current. It is the combination of a couple of opposite poled switches in parallel with the current limiting inductor [29]. The current limiter is used to control the current in case of a fault. In the usual condition the opposite poled switch remains closed. When the fault is sensed, these switches are opened and thereby the fault current starts flowing through the current limiting inductor and limit the current [29].

SCB is used to perform auto reclosing function [29]. It reduces the electrical faults and preserves the huge currents from distribution side. It is used as single, hybrid, static transfer switch. The current and voltage ratings of the breaker illustrates the price tag, constraint of switching devices and breaker losses. It is used as high speed switching device.

STS can be used to shield the sensitive load from voltage sag or swell and thereby serves as protecting device [30]. The advantage of the STS is the continuous supply of load current and there by maintain uninterrupted power to consumers. It is used in high power applications.

The above mentioned CPD possess its own benefits. Among these devices, DVR is examined as unique and most efficient because DVR has many advantages by comparing with the other CPD's. One of the advantages is less expenditure compared to the other devices. Additional justification is that, the DVR has a higher energy capability than other devices. Besides, the DVR is minor in dimension compared to the DSTATCOM [31]. Based on these explanations, the DVR is extensively examined as most effective CPD for mitigating power quality problem. Whenever distortion arises, the control strategy plays significant role to make the DVR in active condition. Among all control strategies, stationary reference frame theory is simple and suitable for DVR. The topology is validated by using SIMULINK/MATLAB.

In section 2, the control strategies of the DVR are discussed. In section 3, the detailed description of proposed theory is discussed. In section 4, result and discussions are explained and section 5 provides the conclusion.

\section{CONTROL STRATEGY OF DVR}

Control strategy is nothing but the process used to control the system and execution of strategic plans. The main concept of control scheme is to sustain constant voltage magnitude at the sensitive load side. In order to mitigate the voltage distortions, the various control strategies of DVR are used and explained as follows.

\subsection{Phase Locked Loop (PLL)}

Phase locked loop acts as a control system, which gives output signal. The phase of the output signal is related to the phase of input signal. It is used to track the phase of the incoming signal [32]. Figure 3 shows that, PLL consists of three elements namely phase detector, Voltage Controlled Oscillator (VCO) and loop filter. The basic concept behind the PLL, the signal from the VCO and the reference signal connected to the input ports of the phase detector. The output from the phase detector is passed to the loop filter. The incoming signal of loop filter is applied to VCO. The error signal which is generated from the phase detector passes through a loop filter which, then manages various assets out of the loop and eliminate the high frequency elements from the signal. Once error signal generated from the loop filter is applied to the control terminal of the VCO. The sense of any variation in this voltage is such that it tries to reduce the phase difference and frequency between the two signals. Initially the loop will be out of lock, and the error voltage will pull the frequency of the VCO towards that of the reference, until it cannot reduce the error any further. At that instant, the loop is locked and hence called PLL.

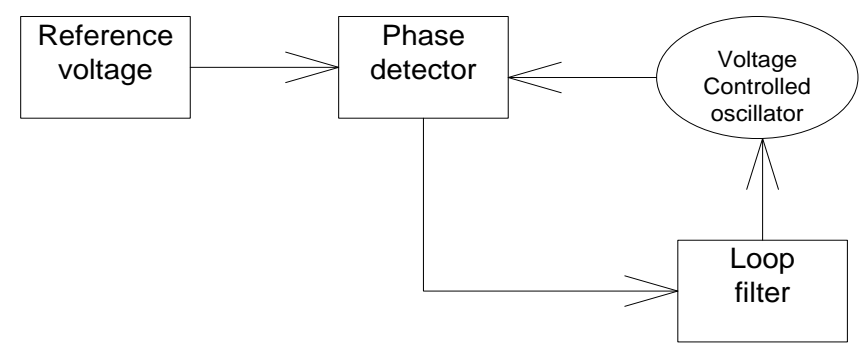

Figure 3. Block diagram of phase locked loop 


\subsection{Reference Frame Theory}

A transformation of variables is used frequently to reduce the complication of the voltage equations that examines the performance of electric machines. The well-known real transformations are attained from the general transformation by simply conveying the speed of the rotation of the reference frame. There are three reference frames and they are as follows:

a. Stationary reference frame theory

b. Rotor reference frame theory

c. Synchronous reference frame theory

\subsubsection{Synchronous Reference Frame Theory}

Among the several control strategies of DVR, synchronous reference frame (SRF) theory is most predictable and suitable for DVR. The main concept as the name suggests is to have a frame which rotates at a synchronous speed [33]. SRF based control method presents excellent features when compared to other methods but it requires PLL technique. This new technique is based on the SRF theory using the PLL for phase locking, so it work under distorted and unbalanced load conditions. The main advantage of SRF theory is that it allows any transformation of space coordinates that does not depend on time.

\section{PROPOSED THEORY}

The proposed control scheme is to sustain constant voltage magnitude at the sensitive load point. In order to mitigate the numerous voltage distortions, the synchronous reference frame (SRF) theory control scheme is implemented, but it requires phase locked loop (PLL). Here PLL acts as a control system and gives output whose phase is related to the phase of input. So it will works under the distorted and unbalanced load conditions. The proposed SRF control scheme uses a-b-c to d-q-o transformations, filters, PLL and inverter as shown in Figure 4. The proposed SRF based theory can be used to resolve power quality problems like voltage sag, swell, harmonics, flickers, voltage unbalance etc. [34]. In this method the control technique of DVR examines the reference voltage to be injected by the injection transformer, by connecting the positive sequence components of the utility voltages with load side line voltages. These utility side voltages are converted into d-q-o and filtering out required component by using filters and then inverse transformation is applied to get a-b-c transformation. Figure 5 shows the block diagram representation of three phase DVR.

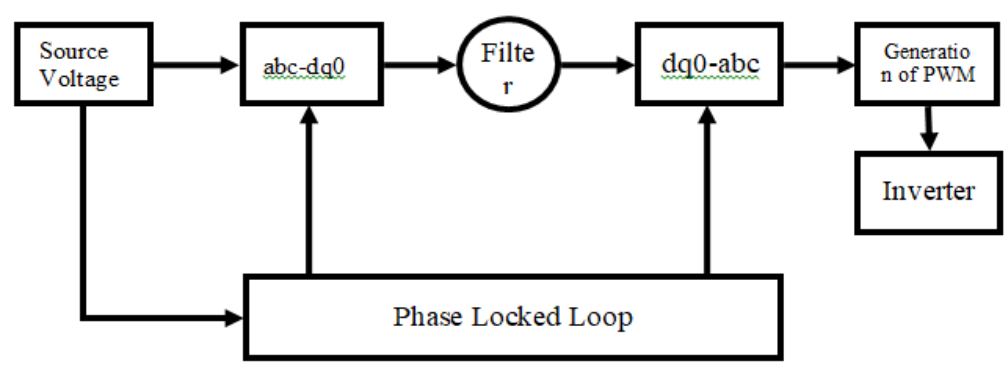

Figure 4. Block diagram of SRF theory [34]

\section{RESULTS AND DISCUSSIONS}

The grid supplying $415 \mathrm{~V}, 50 \mathrm{~Hz}$, to the constant load and DVR is connected in series with the grid line with the help of injection transformer. The three phase fault was created on the utility side and examined how the DVR is operating while utility is under three phase fault condition.

DVR consist of converter which is used for power conversion and injection of voltage with the grid. Injection transformer is useful for voltage injection at determined level towards the grid. In this work, the voltage sag is created from $t=0.03 \mathrm{~s}$ to $t=0.1 \mathrm{~s}$ between two phases and swell occurs from $t=0.2 \mathrm{~s}$ to $0.4 \mathrm{~s}$. In this condition, the three phase voltage across grid is shown in Figure 6 a. It is found that two phases have low voltage from $t=0.03 \mathrm{~s}$ to $\mathrm{t}=0.1 \mathrm{~s}$ during voltage sag and high voltage from $\mathrm{t}=0.2 \mathrm{~s}$ to $0.4 \mathrm{~s}$ during voltage swell, there is occurrence of switching frequency voltages in the converter, remaining switching times it maintains constant voltage. The three phase voltage across the load shown in Figure $6 \mathrm{~b}$, it is found that during occurrence of voltage sag and swell for particular switching period, it maintains constant load voltage due to DVR. The injected voltage of DVR is shown in Figure $6 \mathrm{c}$, it is found that more voltage is injected or absorbed due to occurrence of voltage sag and swell. Harmonics reduces the quality of power. Therefore, the 
filter circuit is used to remove the harmonics. The DVR is able to compensate both the voltage sag as well as swell and maintain the constant load voltage as shown in Figure 6 b. During voltage sag and swell conditions, the DVR provides injected voltage and protects the system from distorted conditions.

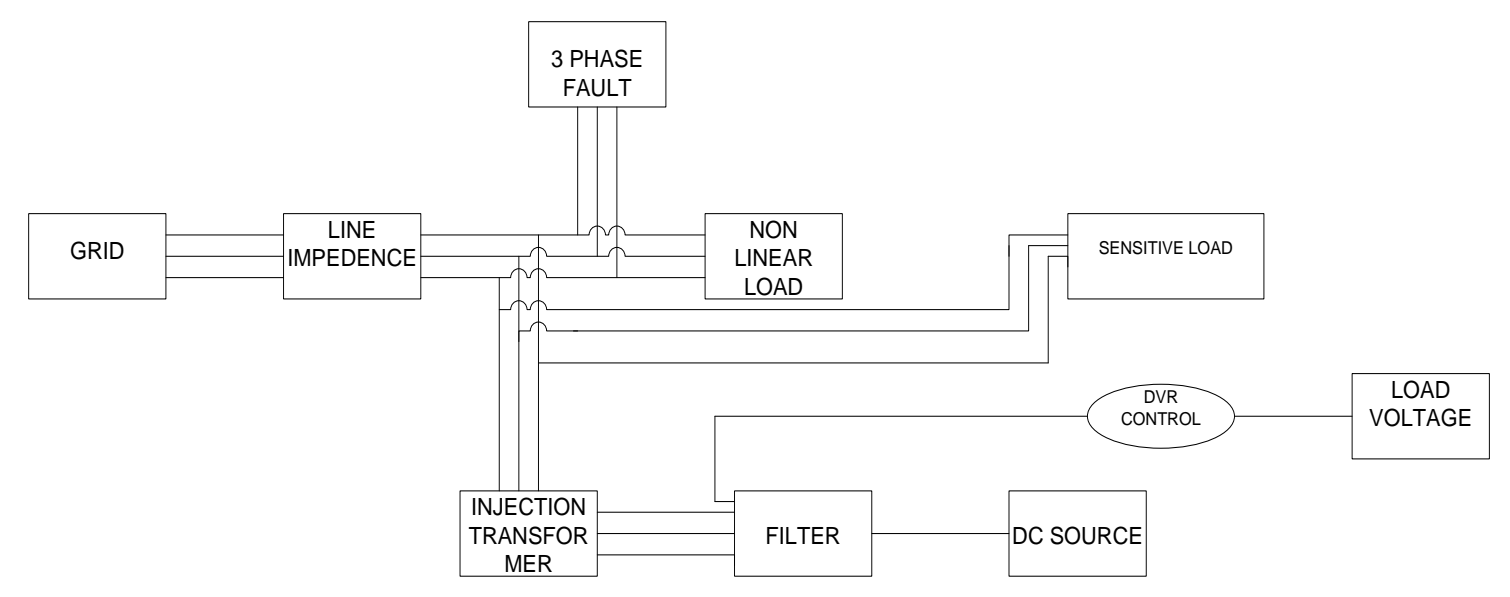

Figure 5. Block Diagram Representation of three phase DVR

Total harmonic distortion (THD) is the measure of effective value distorted wave form and it is defined as the ratio of the sum of the powers of all harmonic components to the power of the fundamental frequency. In power systems, lower the THD means reduction in peak currents, core losses etc. and it is measured by using THD analyzer. A THD measurement can be made by applying a sine wave as an input to a system, and determining the total energy which appears at the output of the system as harmonics of the input frequency. Figure 7 shows the THD for the load voltage under different harmonic order for the fundamental frequency $(50 \mathrm{~Hz})$ and THD of load voltage are $3.95 \%$ which is less than the $5 \%$ limit prescribed in IEEE- 519 standards.
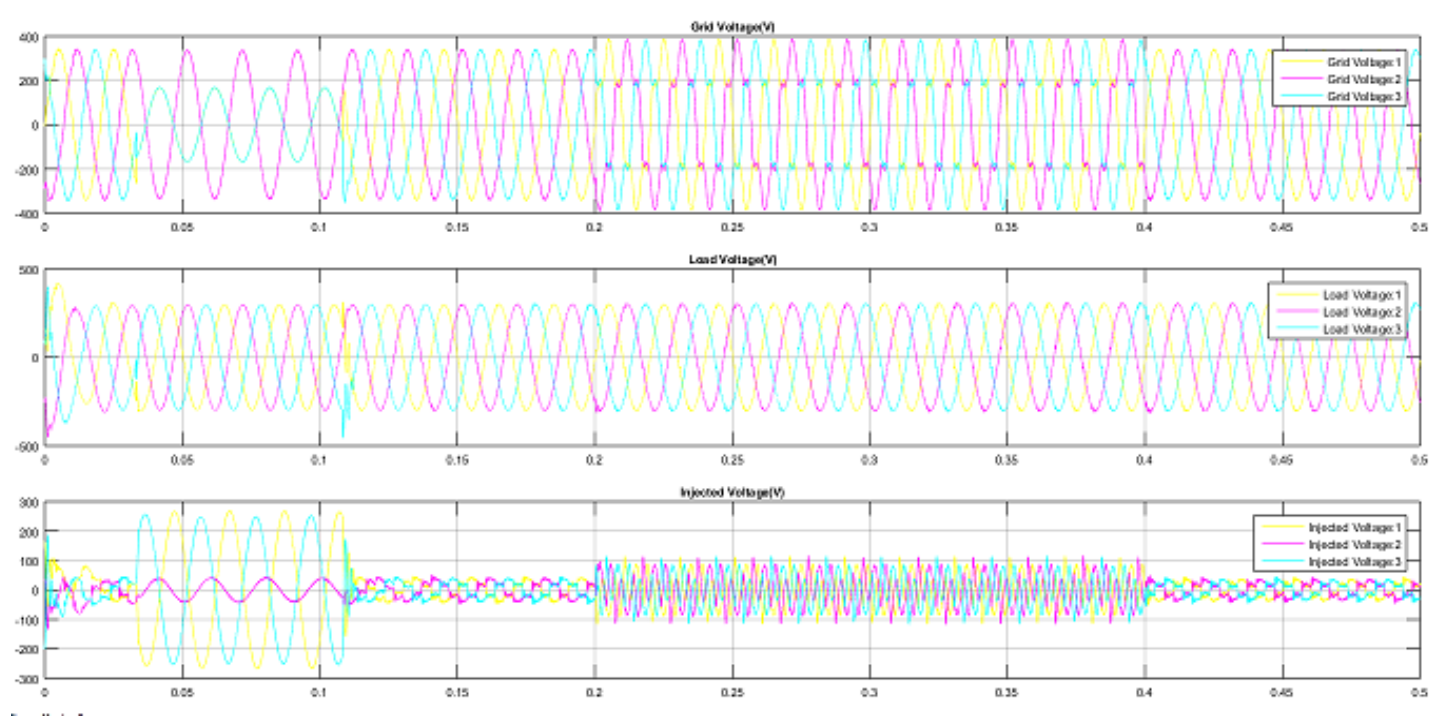

Figure 6. a) Grid voltage, b) Load voltage and c) Injected voltage under Three Phase Fault condition 


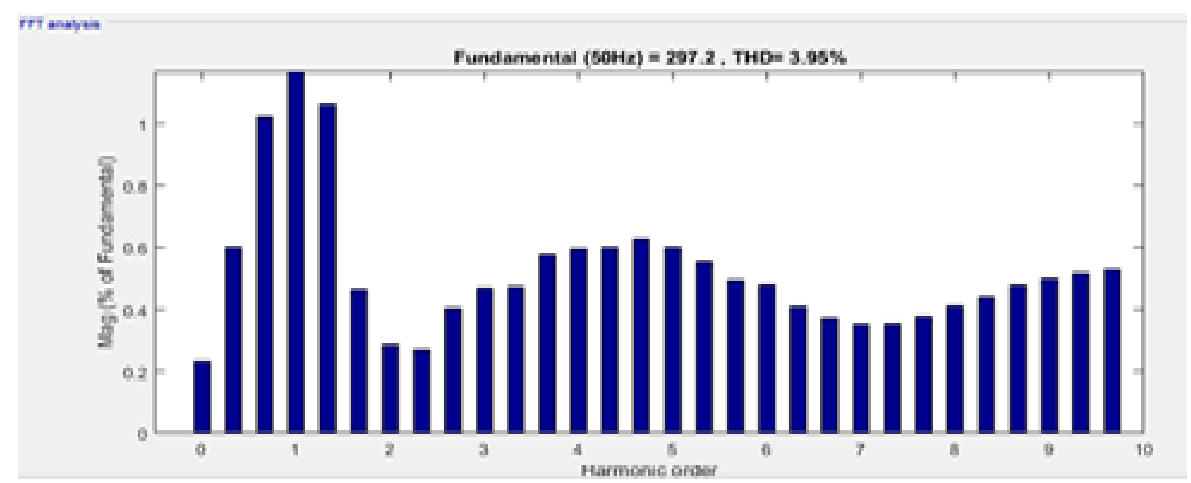

Figure 7. THD for the load voltage under different harmonic order

\section{CONCLUSION}

This paper dispenses the literary text review of different types of CPD for improvement of power quality. The appropriate custom power devices are selected based on system configuration and type of load. It has been found that DVR has superior characteristics such as vibrant reaction to disturbance, less cost and size. The new methodology of control strategy such as synchronous reference frame theory is discussed to improve the power quality using DVR. The overall performance of the DVR is examined under faulty condition. With this control strategy, the simulated output value of THD is found to be $3.95 \%$. DVR is provided to suppress the voltage distortion in utility side. The voltage and current related power quality problems are reduced by using DVR. Thus the DVR obviously dispense the best economic solution for its expanse and capabilities under distortions.

\section{REFERENCES}

[1] Brenna, M., Faranda, R. and Tironi, E, "A new proposal for power quality and custom power improvement: OPEN UPQC,'IEEE Transactions on Power Delivery, vol. 24, no. 4, pp. 2107-2116, 2009.

[2] Anaya-Lara, O. and Acha, E, "Modeling and analysis of custom power systems by PSCAD/EMTDC,"IEEE transactions on power delivery, vol. 17, no. 1, pp. 266-272, 2002.

[3] Xu, Q., Ma, F., Luo, A., He, Z. and Xiao, H, "Analysis and control of M3C-based UPQC for power quality improvement in medium/high-voltage power grid," IEEETransactions on Power Electronics, vol. 31, no.12, pp. 8182-8194, 2016.

[4] Meyer, C., De Doncker, R.W., Li, Y.W. and Blaabjerg, F, "Optimized control strategy for a medium-voltage DVR-Theoretical investigations and experimental results,"IEEE Transactions on Power Electronics, vol. 23, no. 6, pp. 2746-2754, 2008

[5] Desale, P.A.,Dhawale, V.J. and Bandgar, R.M, "Brief review paper on the custom power devices for power quality improvement, "International Journal of Electrowwwwwnic and Electrical Engineering, vol. 7, no. 7, pp. 723-733, 2014.

[6] Gupt, S., Dixit, A., Mishra, N. and Singh, S.P, "Custom power devices for power quality improvement: a review," International Journal of Research in Engineering \& Applied Sciences, vol. 2, No. 2, pp.1646-1659, 2012.

[7] Devaraju, T., Reddy, V.V. and Kumar, M.V, "Role of custom power devices in Power Quality Enhancement: A Review, "International Journal of Engineering Science and Technology, vol. 2, no. 8, pp. 3628-3634, 2010.

[8] Babaei, E. and Kangarlu, M.F, "Voltage quality improvement by a dynamic voltage restorer based on a direct three-phase converter with fictitious DC link,"IET generation, transmission \& distribution, vol. 5, no. 8, pp. 814823.2011.

[9] Jothibasu, S. and Mishra, M.K, "A control scheme for storageless DVR based on characterization of voltage sags,"IEEE transactions on power delivery, vol. 29no. 5, pp. 2261-2269, 2014.

[10] Remya, V. K., P. Parthiban, V. Ansal, and Avinash Nandakumar. "Single-Phase DVR with Semi-Z-Source Inverter for Power Distribution Network." Arabian Journal for Science and Engineering, pp. 1-15, 2018.

[11] Milanovic, J.V. and Zhang, Y, "Modeling of FACTS devices for voltage sag mitigation studies in large power systems," IEEEtransactions on power delivery, vol. 25, no. 4, pp. 3044-3052, 2010.

[12] Zhang, Y. and Milanovic, J.V, "Global voltage sag mitigation with FACTS-based devices," IEEE Transactions on Power Delivery, vol.25no. 4, pp. 2842-2850, 2010.

[13] de Almeida Carlos, G.A., Jacobina, C.B., Méllo, J.P.R.A. and dos Santos, E.C, "Cascaded open-end winding transformer based dvr," IEEE Transactions on Industry Applications, vol. 54, no. 2,pp. 1490-1501, 2018.

[14] Babaei, E., Kangarlu, M.F. and Sabahi, M, "Mitigation of voltage disturbances using dynamic voltage restorer based on direct converters," IEEE Transactions on Power Delivery, vol. 25, no. 4, pp. 2676-2683, 2010.

[15] Li, Y.W., Loh, P.C., Blaabjerg, F. and Vilathgamuwa, D.M, "Investigation and improvement of transient response of DVR at medium voltage level,"IEEE transactions on industry applications, vol.43, no. 5, pp. 1309-1319, 2007. 
[16] Rauf, A.M. and Khadkikar, V, "An enhanced voltage sag compensation scheme for dynamic voltage restorer," IEEEtransactions on industrial electronics, vol. 62, no. 5, pp. 2683-2692, 2015.

[17] Vilathgamuwa, M., Perera, A.R. and Choi, S.S, "Performance improvement of the dynamic voltage restorer with closed-loop load voltage and current-mode control,"IEEE Transactions on Power electronics, vol. 17, no. 5, pp. 824-834, 2002.

[18] Saeed, A.M., Aleem, S.H.A., Ibrahim, A.M., Balci, M.E. and El-Zahab, E.E, "Power conditioning using dynamic voltage restorers under different voltage sag types," Journal of advanced research, vol. 7, no. 1, pp. 95-103, 2016.

[19] Balamurugan, C.R. and Vijayalakshmi, K.," Comparative Analysis of Various Z-source Based Five Level Cascaded H-bridge Multilevel Inverter," Bulletin of Electrical Engineering and Informatics(BEEI), vol. 7, no. 1, pp.1-14, 2018.

[20] Omar, Rosli, et al, "Comparative Study of a Three Phase Cascaded H-Bridge Multilevel Inverter for Harmonic Reduction," Indonesian Journal of Electrical Engineering and Computer Science(IJEECS), vol.14, no.3, pp. 481492, 2015.

[21] Balamurugan, ChinnapettaiRamalingam, et al, "A review on modulation strategies of multi-level inverter," Indonesian Journal of Electrical Engineering and Computer Science(IJEECS), vol.3, no.3, pp. 681-705, 2016.

[22] Ara, A.L., Tolabi, H.B. and Hosseini, R, "Dynamic modeling and controller design of distribution static compensator in a microgrid based on combination of fuzzy set and galaxy-based search algorithm," International Journal of Engineering-Transactions A: Basics, vol. 29, no. 10,pp. 1392-1400, 2016.

[23] Mala, R.C., Prabhu, N. and HV, G.R., "Performance of STATCOM-ES in Mitigating SSR," .International Journal of Power Electronics and Drive Systems (IJPEDS), vol. 8, no. 4, pp.1822-1829, 2017.

[24] Reddy, S.R., Prasad, P.V. and Srinivas, G.N., "Design of PI and Fuzzy Logic Controllers for Distribution Static Compensator", International Journal of Power Electronics and Drive Systems (IJPEDS), vol. 9, no. 2, pp.465-477, 2018.

[25] Singh, B., Jayaprakash, P. and Kothari, D.P, “A T-connected transformer and three-leg VSC based DSTATCOM for power quality improvement, "IEEE Transactions on Power Electronics, vol. 23, no. 6, pp. 2710-2718, 2008.

[26] Ajitha, P. and Jananisri, D., "Voltage Sag Mitigation and Load Reactive Power Compensation by UPQC," Bulletin of Electrical Engineering and Informatics(BEEI), vol. 3, no. 2, pp.109-112, 2014.

[27] Desale, P.A., Dhawale, V.J. and Bandgar, R.M, "Brief review paper on the custom power devices for power quality improvement," International Journal of Electronic and Electrical Engineering, vol. 7, no.7, pp. 723-733, 2014.

[28] Samal, S. and Hota, P.K., "Wind Energy Fed UPQC System for Power Quality Improvement," Bulletin of Electrical Engineering and Informatics, vol. 7, no.3, pp.495-504, 2018.

[29] Ghosh, A. and Ledwich, G, "Power quality enhancement using custom power devices," Springer Science \& Business Media, 2012.

[30] Moschakis, M.N. and Hatziargyriou, N.D, "A detailed model for a thyristor-based static transfer switch,"IEEE Transactions on Power Delivery, vol. 18, no. 4,pp. 1442-1449, 2003.

[31] Benachaiba, C. and Ferdi, B, "Voltage quality improvement using DVR," Electrical Power Quality and Utilisation. Journal, vol. 14, pp. 39-46, 2008.

[32] Viet, D.T., Hieu, N.H., Le Hoa, N. and Khoa, N.M.," A control strategy for dynamic voltage restorer," In Power Electronics and Drive Systems (PEDS), 11th International Conference on IEEE, pp. 1106-1110, 2015.

[33] Lee, R.J., Pillay, P. and Harley, R.G., "D, Q reference frames for the simulation of induction motors," Electric power systems research, vol. 8, no.1, pp.15-26. 1984.

[34] Kohila, J., Kannan, S. and Kumar, V.S., "Control of dynamic voltage restorer for injecting active power using synchronous reference frame theory," In Circuit, Power and Computing Technologies (ICCPCT), 2015 International Conference on IEEE, pp. 1-6, 2015.

\section{BIOGRAPHIES OF AUTHORS}

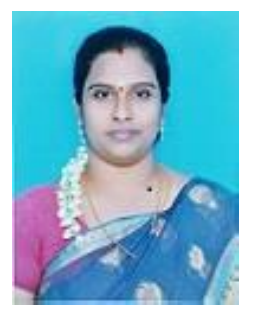

D. Danalakshmi was born in Chennai, Tamilnadu, India. She has received her B.E. degree in Electrical and Electronics Engineering from Thiagarajar College of Engineering, Madurai, affiliated to Madurai Kamaraj University, India in 2003 and M.E. degree in Power Systems Engineering from Thiagarajar College of Engineering, Madurai, affiliated to Anna University, Chennai, Tamil Nadu, India, in 2006. She has completed her Ph.D. degree in Kalasalingam University in September 2017. She has received the Advanced Mission 10X learning approach practitioners certificate and her assignments were made available in Wipro Mission 10X portal. She has been awarded with the appreciation certificate from Indian Institute of Technology, Kharagpur as topper for NPTEL online certification exam on "Power system" conducted on October 2017. She is a life member of Indian Society for Technical Education (ISTE). She has worked as an Assistant Professor in the Department of Electrical \& Electronics Engineering, Kalasalingam University, Krishnankoil, Virudhunagar District, Tamil Nadu, India for eight years. Then, she has worked as an Assistant Professor in the Department of Electrical \& Electronics Engineering, AAA college of Engineering and Technology, Amathur, Sivakasi, Tamil Nadu, India for two years. Then, She worked in Madanapalle Institute of Technology. Presently, she is working as Associate Professor in the Department of Electrical \& Electronics Engineering, GMR 
Institute of Technology, Andhra Pradesh. She has attended several International conferences and presented papers also. She is actively involved in research for the past five years. She is presently working in the area of Power System Optimization and Smart Grid.

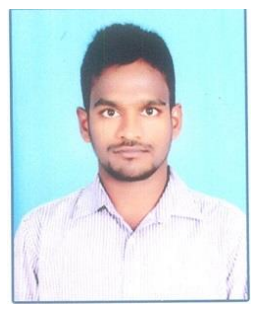

B. Srinivasarao was born in Palakonda, Andhra Pradesh, India. He completed his B.Tech degree in Electrical and Electronics Engineering from Aditya institute of technology and management, Tekkali, affiliated to JNTUK University, India in 2003 and now he is pursuing his master's degree in GMR institute of technology. His area of interest is Power Quality.

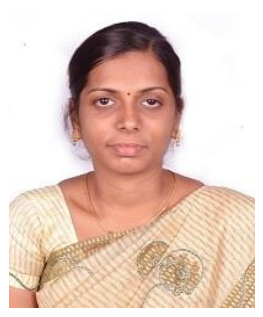

Mrs. J. Kohila received a BE (EEE) from Anna University, Chennai and ME (Power Electronics and Drive) from Anna University, Coimbatore in 2009 and 2011 respectively. She is pursuing Ph.D. from Kalasalingam Academy of Research and Education. Currently she is working as Assistant Professor in Department of Electrical and Electronics Engineering, Kalasalingam Academy of Research and Education, Tamil Nadu, India where she has been working since 2011. She has more than 7 years of teaching experience. Her area of interest is Power Quality Improvement, Solar and wind Energy Conversion. 